\section{Predictive validity of a Rashevsky-Landahl neural net: Test of a model of
masking for form*}

\author{
D. L. SCHURMANt \\ University of Illinois, Urbana-Champaign, Champaign, Illinois 61820
}

The predictive validity of Weisstein's (1968) Rashevsky-Landahl neural net model was tested in this series of studies. No U-shaped masking functions were obtained with trained Ss for a recognition task. The implications of this failure to verify the predictions of Weisstein's model for the whole monotonic vs nonmonotonic masking controversy is discussed. Possible reasons for the predictive failure are also discussed.

Meta- and paracontrast effects, usually defined as backward and forwand making of a form by a spatially adjacent, nonovertapping form, have been subject to extensive rewearch (see Kahneman, 1968, for a full review). Weisstein (1968) has proposed a model of visual procensing designed to explain meta- and paracontrast effects well as the U-shaped functions sometimes obtained for these effects. This model is based on a Rashevaky-Landahl type of neural net, in which both excitatory and inhibitory neurons converge on a single transmitting neuron. The model consists of five two-factor neurons. Two sets of sequential neurons, one pair excited by the target and the other pair excited by the mask, converge on a final decision neuron. The assumption of Weisstein's model is that those neurons excited by the target have an excitatory synapse with the final neuron, whereas the neurons excited by the mask have an inhibitory synapse with the final neuron. Thus, the inhibitory neurons have a modulating effect on the output of the decision neuron.

The explanation of meta- and paracontrast in Weisstein's model is based on the assumption of different latencies for the excitatory and inhibitory neural effects on this decision neuron. This assumption seems to be based on the findings of Ratliff and Hartline (reported in Ratliff, Hartline, \& Miller, 1963) of both excitatory and inhibitory effects for spots of light shown in the compound eye of Limulus polyphemus. Longer latencies were obtained for inhibitory effects than

\footnotetext{
*This research was supported by NIH *This research was supported by NIH
rant MH01206 to C. W. Eriksen. Portions rant MHO1206 to C. W. Eriksen. Portions
f this research were reported at the 1969 leeting of the Midwestern Psychological ssociation.

tPresent address: Department of Tresent address: Department of
ychology, Emory University, Atlanta, zorpia 30322.
}

for excitatory effects in these studies. In Weiatein's model, inhibitory effects of a dark spot upon an adjacent dark target are assumed to be more rapid than the excitatory effects of the target, the logical converse of Hartline's findings.

Weirstein has attempted to explain both monotonic and nonmonotonic masking functions found in the previous literature on the masking of forms by forms. Monotonic functions are those referred to as Type $A$ functions by Weisstein, and reflect masking effects which decrease monotonically from simultaneous presentation of mask and target as the asynchrony of the mask and target increases. Nonmonotonic functions are those in which maximum masking occurs at some point other than simultaneous presentation of mask and target. Thus, backward and forward masking, or meta- and paracontrast, are considered to be separate functions.

There are three basic assumptions in Weisstein's model. Two of these assumptions are explicit in the paper and are: (1) inhibition effects have shorter latencies than facilitatory effects, in the human visual system, given equal stimulus energy, and (2) the inhibitory and excitatory neurons must converge on a single unit which receives information from all overlapping receptive fields. A third assumption is not explicitly stated in the paper but appears to be implicit in the model. This assumption is that the general inhibitory effects of adjacent dark areas are the logical converses of the effects of adjacent light areas, found by Ratliff et al (1963) (Weisstein, 1968, p. 505). From the standpoint of the physical optics of the eye (light scattering, bending, diffusion, etc.), this assumption may be difficult to support. There are some problems with Weisstein's model, primarily concerned with the model's being derived from the data of
Weisstein and Haber (1965). The difficulties in these data have been extensively criticized, primarily on methodological grounds, by Eriksen, Collins and Greenspon (1967) and Eriksen, Becker, and Hoffman (1970). Whether these criticisms are or are not justified is still a matter of debate.

Despite these possible problems, Weisstein's model has a virtue too seldom found in perceptual procesaing models. That is, the model makes specific testable predictions possible.

The model predicts that U-shaped (nonmonotonic) masking functions will be obtained and maximum masking will occur at $40-60 \mathrm{msec}$ of stimulus onset asynchrony when the following conditions are satisfied: (1) the mask is a ring surrounding the target, (2) the mask and target are of equal duration $\left(T / M_{d}=1\right.$, in Weicutein's terminology), (3) the mask and target are of equal intensity or, in the case of black-on-white stimuli, of equal contrast $\left(T / M_{2}=1\right.$, in Weirstein's terminology), and (4) the makk and target are of equal stroke width or thicknes (Weinstein, 1968).

Although previou experiments, such as Eriksen et al (1970) and Eriksen and Marshall (1969), have tried to replicate the U-shaped masking functions obtained by Weisstein and Haber (1965), no specific test of the model itself has been performed. The experiments reported below were designed to meet the four above conditions and thus to assess the predictive validity of this model. The pilot study is reported in some detail because of the methodological changes that resulted from it.

\section{PILOT \\ Subjects}

Three graduate students and one faculty member served as paid Ss. Two of the Ss were female. All Ss had normal or corrected to normal vision. Three Ss had never participated in visual perception experiments.

\section{Apparatus}

The stimuli were presented on a 10-channel projection tachistoscope, which has been described elsewhere in detail (Eriksen, Schurman, \& Richter, 1969). Briefly, this is a projection tachistoscope that uses separate projectors for each channel. The target stimuli were black-on-white slide transparencies of the News Gothic capital letters $A, T$, and $V$. The ring mask was a black-on-white circle. When projected, the letters subtended a vertical visual angle of $12 \mathrm{~min}$ and the ring mask subtended an angle of $16 \mathrm{~min}$ at the outside diameter. The stroke width of the letters and the mask was $1.75 \mathrm{~min}$ of angle. All 
viewing was monocular with the dominant eye at viewing distance of $1.9 \mathrm{~m}$ (72 in.).

Each stimulus was presented by a different projector. Changing from one stimulus to another was accomplished by electronically switching the projectors; thus, the alignment of mask and target remained unchanged for all trials and conditions. Two projectors were used to project the blank adaptation field in order to maintain constant contrast and luminance ratios. One projector went off whenever the target stimulus came on, and the other went off whenever the mask was on. Since the original contrast between figure and ground was $99+\%$ for the etimuli, the contrast ratio was approximately $50 \%$ with this arrangement.

The luminance of the ground was $2 \mathrm{~mL}$, measured and equated for the six projectors by means of a MacBeth illuminometer. The on times and delay times were controlled by an Iconix 6255 time-bage generator and two Iconix 6010 preset controllers. Timing was checked periodically throughout the experiment with a Tektronix 502A oecilloscope and never varied more than $0.1 \%$. The fixation point was a black cross, $10 \mathrm{~min}$ of angle in height, located $15 \mathrm{~min}$ of angle below the bottom of the mask. The fixation cross was always present.

\section{Procedure}

The Ss served in 2-4 practice sessions with only the letter present prior to the experimental sesaions. During the practice sesions, the duration at which each $\mathbf{S}$ identified the target letters alone with $\mathbf{8 0 \%}$ accuracy was determined. These durations ranged from 18 to 25 msec and were used for each $s$ throughout the experiment. The mask duration was equal to the target duration for each $\mathbf{S}$. There were eight conditions: mask preceding target by -20 msec, 0 -msec interstimulus interval (ISI), simultaneous presentation of mask and target, and mask following target by $+0,20,40,60$, and 100 msec ISI. Each letter was presented equally often in an otherwise random order for each block of 12 trials. All eight experimental conditions were presented in each sevaion, one block per condition. The order of conditions was partially counterbalanced acroes Ss and sescions with a randomized Latin-square design. All trials were $\mathrm{S}$ initiated. Euch $S$ received 192 trials under each condition in 16 sessions.

\section{Results and Discussion}

This study was essentially a pilot study to test both the methods and the equipment. We found that naive Ss yielded nonmonotonic backward masking functions under these conditions for the first two or three sessions (24-36 trials/condition). The Ss' masking function shifted rather abruptly to strictly monotonic for both backward and forward masking as the sessions progressed. The experienced $S$ never showed a nonmonotonic mesking curve. Reports from our $3 s$ and observations by $E$ indicated that the Ss' task changed as the ISI increased to the point at which target/mask asynchrony became detectable. That is, then the asynchrony between onset of target and mask was not detectable, Ss' task was to discriminate between the complex but unitary patterns of a-letter-in-a-ring. As the asynchrony of the mask and target onsets became detectable, the task shifted to a discrimination between two simple patterns, identifying one of them and ignoring the other. The point at which asynchrony began to be detectable is the point at which naive $S$ s showed poorest accuracy until they learned, apparently, to adopt the strategy of always concentrating on the target letter. Naive Ss did report just such a strategy change after the first few sessions.

The neurological basis of Weisstein's model implies little or no effects of experience on masking (however defined) as a function of stimulus onset aynchrony (SOA). Nor is there any provition in the model for changes in the latency differences between inhibitory and facilitatory neural effects due to experience. Thus, the finding of U-thaped masking functions which rapidly changed to monotonic functions with practice indicates that these U-shaped functions are artifactually produced from the point of view of the model as well as from our own point of view. In order to eliminate this strategy shift without requiring extensive practice for all $\mathrm{Ss}$, a procedure of giving a preview of each condition was adopted. This preview is described in detail in Experiment 1.

\section{EXPERIMENT 1 \\ Subjects}

Two male graduate students and one male facuity member served as paid volunteers. All Ss had normal or corrected to normal vision. All Ss had had previous experience in visual perception tasks.

\section{Apparatus}

The apparatus was the same as that used in the pilot.

\section{Procedure}

The procedure was the same as in the pilot, with the following change. Before each block of trials in the experimental sessions, Ss were shown each letter and the mask in that ISI condition. The letter was identified beforehand, and the $S$ was given one "free look." For example, E would say, "This is an $A_{2}$ " then present the letter with the mask occurring at the appropriate ISI. Accuracy and condition were never correlated for any $S$ until he had finished the entire experiment. The $\mathrm{E}$ never confirmed or denied Ss' hypotheses as to which condition had been presented in the previous block of trials. Therefore, Ss should not have been able to bias their responses differentially for all ISIs at which stimulus asynchrony was not apparent. Each 5 received 96 trials/condition in eight sessions.

\section{Results and Discussion}

As can be geen in Fig. 1, maximum masking occurred at simultaneous presentation of stimulus and mask, although the data are quite noisy. All So showed maximum masking at this point, as can be from the individual $s$ points in the graph. No reversals occurred for any $S$ in the region from -20 mece to simultaneity and in the region from simultaneity to +20 -msec ISI (SOAs of \pm 37 to \pm 45 msec, depending on S's durations). These results were tested for the region of \pm 20 -msec ISI by a three-way analysis of variance (ISI by Backward/Forward Making by Ss). The effect of ISI was significant beyond the .05 level of confidence $[F(2,4)=13.76]$. Although there is apparent asymmetry between backward and forward masking in Fig. 1, it was not significant. Similarly, the interaction of backward/forward masking ISI was not simificant $[F(2,4)=1.66, n>.20]$. Note that, had the "preview" procedure biased Ss' responses, the Ss would have shown a flat portion in the masking curve at all ISIs in which asynchrony was not detectable. As can be seen in Fig. 1, this flattening of the curve occurred for only one $S$.

These results, however, only indicate that Weisstein's model is quantitatively inaccurate. That is, nonmonotonic masking might be occurring in our experiment, but not at the 40 - to $60-$ msec $5 O A$ predicted by Weisstein. As Weisstein (1968) has pointed out, the use of ISI values means that \pm 0 -msec ISI is equal to SOA (or Feisstein's $\Delta t$ ) of $\pm 17-25$ msec. The apparent asymmetry of Fig. 1 could support the argument that maximum masking is occurring at a point between simultaneous presentation and consecutive presentation of target and mask. Thus, the masking function could be nonmonotonic, but this could be hidden by the use of ISI as the time parameter. Experiment 2 was designed 


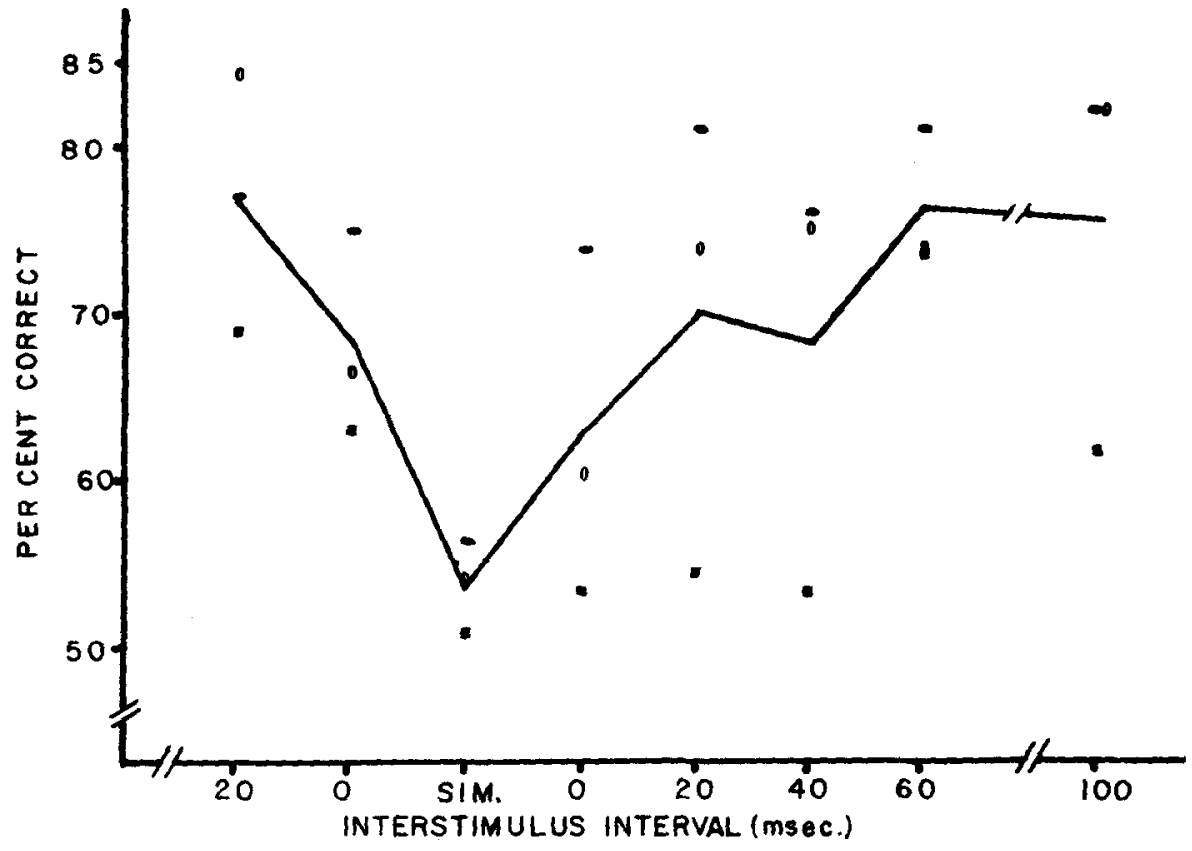

Fig. 1. Masking of a form by a surrounding ring. The line is the average of all Ss; individual points are individual $S$ scores.

to yield a finer-grained analysis of the course of masking between simultaneous and consecutive presentation of mask and target, as well as to allow generalization of these procedures to naive Ss.

\section{EXPERTMENT 2 Subjects}

Three undergraduate students (one male) served as paid volunteers. All Ss had normal or corrected to normal vision. None had had any previous experience in visual perception tasks.

\section{Apparatus}

The same apparatus was used as in the pilot and in Experiment 1.

\section{Procedure}

The same procedure was followed as in Experiment 1, with the following exception. The base duration for each S Was determined for the $70 \%$ recognition accuracy level rather than an $80 \%$ base level. The $70 \%$ base level (target alone) was used in order to increase the sensitivity and linearity of the response measure. These durations were used throughout the experiment and were 21, 23, and 30 msec for the three Ss. Eight conditions were presented: \pm 0 -msec ISI (consecutive presentation of mask and target), $\pm 1 / 3$ ind $\pm 2 / 3$ overlap of mask and target, imultaneous presentation of mask and arget, and an additional +300 -msec SI condition. The +300-msec ISI ondition was included because one $S$ 1 Experiment 1 showed masking still ccurring at 100-msec ISI. Each S the preceding experiment, every $S$ showed maximum masking when the target and mask were presented simultaneously. The analysis of variance showed the effect of ISI to be only approaching significance $[F(3,6)$ $=3.96,4.76$ required at the .05 level]. However, significant masking effects were shown when the mean errors for the simultaneous and consecutive presentation were tested alone ( $t=$ 4.93, $\mathrm{df}=46$ for forward masking, $t=$ 2.84, df $=46$ for backward masking, $p<.01$ ). No other effects or interactions approached significance. These results showed no possibility of a U-shaped masking function for this recognition task.

To the best knowledge of the author, all of Weisstein's conditions (Weisstein, 1968) were met for the prediction of maximally nonmonotonic masking functions in these experiments. Failure to obtain U-shaped masking functions for recognition accuracy as predicted, therefore, warrants a more critical and detailed examination of the a priori problems of Weisstein's model received 192 trials under each condition in 16 sessions.

\section{Results and Discussion}

As can be seen in Fig. 2, both backward and forward masking were again monotonic from simultaneous presentation of mask and target. As in mentioned in the introduction of this paper. Probably the least debatable problem is that of assumed equivalence of inhibitory effects between adjacent lighted areas and adjacent dark areas of the visual field. When a lighted spot is projected into the eye, scattering and bending of the

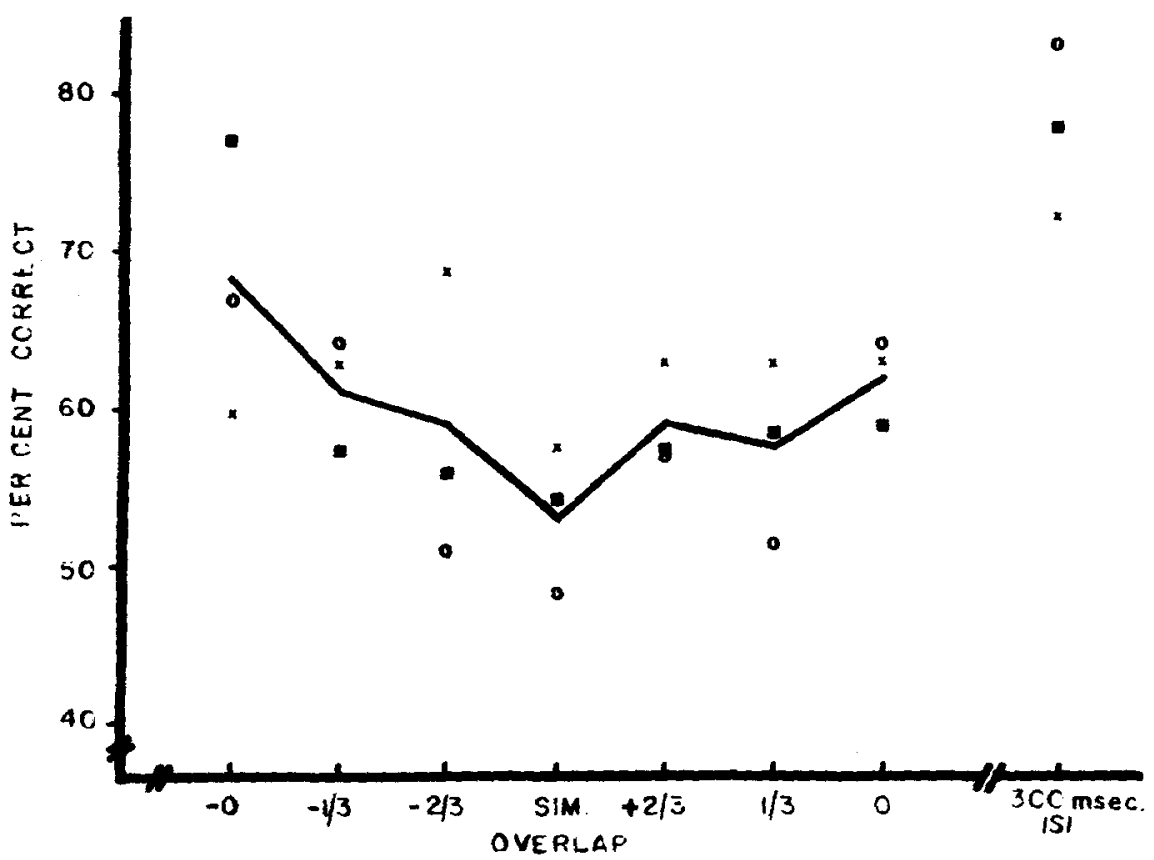

Fig. 2. Masking of a form by a surrounding ring when the stimuli are temporally overlapping. The line is the average of all Ss; individual points are individual $\mathbf{S}$ scores. 
light rays occur in the aqueous and vitreous humors and the crystalline lens (Bartley, 1969). Thus, if luminous flux and contrast are held constant, the diameter of the light spot can be reduced until it approaches a theoretical point source, but the effective diameter on the retina will not become less than 2 to $5 \mathrm{~min}$ of angle (Ricco's law). On the other hand, reduction of the diameter of a dark spot will cause it to disappear from the field altogether, even though, in terms of geometrical optics, the diameter is still finitely large. The disppearance of a dark spot with a constant luminous flux and contrast is due to the same bending and scattering of light rays in the eye. In addition, a rather perplexing problem occurs from the neurological level-which of the neural pulses should be considered inhibitory and which facilitatory for dark stimuli as opposed to light stimuli? For further information on this point, see Uttal (1971).

The methodological adequacies of the studies (Weisstein, 1966; Weisstein \& Haber, 1965) upon which Weisstein's model is based is a matter of continuing debate. However, this debate seems to have polarized investigators of visual masking into two more or less distinct groups. One group-Weisstein, Haber, and others-can be characterized as the U-shaped or nonmonotonic masking group. The opposing group-Eriksen, Schiller, Kahneman, and others-can be characterized as the monotonic masking group. Careful research of the controversy that has been raging in the visual masking literature for several years (see Kahneman, 1968; Eriksen, Becker, \& Hoffman, 1970, for reviews) forces the conclusion that the controversy may be due more to definitional differences than to theoretical ones.

The U-shaped masking group seems to accept Weisstein's definition of masking as "... raising of the threshold of a target stimulus or the occlusion from perception of a supra-threshold target stimulus by the presence of another masking stimulus [Weisstein, 1968, p. 494]." The monotonic masking group tends to follow Eriksen's lead in defining masking as a change in recognition or detection accuracy caused by the presence of a masking stimulus (Eriksen \& Steffy, 1964). The lack of congruence for a definition of masking has led to the paradox of a citation of one set of data as support for both positions.

For instance, Weisstein states:
"Similarly, when Schiller and Smith (1966) use a lighted disc and ring as target and mask respectively, each at a luminance of $43 \mathrm{ft}-\mathrm{L}$. and a duration of $5 \mathrm{msec}$, they have obtained a $U$ minimum at about -65 msec $\Delta t, \ldots$. Here again, with $T / M_{a}$ and $T / M_{d}$ equal to 1 , the U-minimum is as predicted, moreover, when they decreased $T / M_{a}$ to .01 and $.001 \ldots$ they obtained monotonic detection functions [1968; p. 5111." However, in the cited article, Schiller and Smith state: "Our results may be summarized as follows: 1) Although the phenomenal brightness of a disk, when followed by a ring at ISI's of between 50 and 100 msec is reduced, CRT to the disk is equally rapid at all ISI's . . . 2) In a forced choice comparison situation, no $U$-shaped function is found for either CRT or for correctness of report. This meta-contrast effect does not seem to involve the obliteration of the first stimulus, as it is equally detectable at all IST's... [Schiller \& Smith, 1966, p. 381." The implication is that changes in phenomenal brightness are accepted as masking by the U-shaped masking group. Presumably when, as here, two or more measures yield conflicting functions, the results that fit the model are the result noted. For instance, in neither Schiller and Smith's nor Eriksen's research (Eriksen \& Marshall, 1969; Eriksen, Becker, \& Hoffman, 1970) did reaction time, recognition accuracy, and detection accuracy seem to be linearly related to phenomenal brightness.

Briksen and his associates feel that phenomenal brightness is a different phenomenon from detection and recognition responses and could therefore follow different laws. Thus, brightness changes should be examined separately from masking phenomena. Insofar as this position is correct, the likelihood of accounting for both detectability changes and phenomenal brightness changes using a single explanatory model is remote. The controverny between U-shaped and monotonic masking functions is unlikely to be resolved until masking is clearly defined.

My conclusions may be summarized as follows: (1) Uthaped masking functions are not obtained with recognition or detection tasks, even though the conditions for maximal U-shaped functions are met. (2) Weisstein's Rashevsky-Landahl neural net model does not accurately predict the course of masking of a form by an adjacent nonoverlapping form. (3) The question of monotonic vs U-shaped masking functions will not be answered until an unambiguous definition of the term "masking" is agreed upon. (4) In view of the markedly different functions obtained for changes in phenomenal brightness and detection or recognition accuracy as a result of adjacent nonoverlapping stimuli (Schiller \& Smith, 1966), I suggest the term "metacontrast" be reserved for changes in phenomenal brightness of a target and the term "masking" be reserved for changes in recognition or detection accuracy.

\section{REFERENCES}

BARTLEY, S. H. Principles of perception. New York: Harper \& Row, 1969.

BROWN, J. L. Ficker and intermittent stimulation. In C. H. Graham (Ed.). Vition and visual perception. New York: wiley, 1965. Chap. 10.

ERIKSEN, C. W." BECKER, B. B., \& HOFFMAN, J. C. Safari to madking land: $A$ hunt for the elusive U. Perception \& Psychophysics, 1970, 8, 245-250.

ERIKSEN, c. W., COLLINS. J. F.. \& GREENSPON, $T$, An andysis of certain factors responsible for nonmonotonic back ward masking functions. Joumal of Experimental Psychology, 1967, 75, 500-507.

GRIKSEN, C. W B MARSHAI, P. H Fallure to replicate a reported U-shaped visual masking function. Psychonomic Science, 1969, 16, 196-196.

ERIKSIA, C. W. SCHURMAN, D. I., \& RICHTSR, 0 . N-channel tachistoscopes. Behavior Research Methods \& Instrumentation, 1969, 1, 118-122.

ERIKSIN, C. W., \& STIFFY, R. A. Short-term memory and retrosctive interference in visual perception. Joumal of Expertmental Psycholoty, 1964,68, 423-434.

KAINBMAN, D. Method, findings, and theory in studies of visual masting. Psychological Bulletin, 1968, 70, $404-425$.

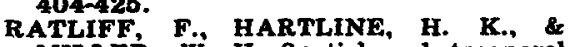
MILLER, W. H. Spatial and temporal aspects of retinal inhibitory interaction. Journal of the Optical Society of America, 1963, 53, 110-120.

SCHILLER, P. H., \& SMITH, M. C. Detection in metacontrast. Journal of Experimental Psychology, 1966, 71, 32-39.

UTTAL, W. R. Paychoblological silly season-or-what happens when neurophysiological data become psychological theories. Jouknal of General Psychology, 1971, 84, 161-166.

WEISSTEIN, N. Backward masting and models of perceptual processing. Joumal of Experimental Psychology, 1966, 72, 232-240.

WEISSTEIN, N. A Rashevsky-Landahl neural net: Simulation of metacontrast. Psychological Review, 1968, 75, 494-521. WEISSTEIN, N., H HABER, R. N. A U-shaped backward maxins function in viton. Psychonomic Science, 1965, 2 , 75-76.

(Accepted for publication March 24, 1972.) 